\title{
TEATRO COMO UMA FERRAMENTA DE FORMAÇÃO POLÍTICA PARA AS INTEGRANTES DO GRUPO “MMC: RESISTÊNCIA E ARTE” \\ Letícia Pereira*
}

\section{Resumo}

Este artigo pretende trazer o processo construído e vivenciado pelas mulheres camponesas militantes do Movimento de Mulheres Camponesas (MMC) no grupo de teatro MMC: Resistência e Arte. A metodologia se deu através da análise de duas peças teatrais, construídas e interpretadas por elas durante as oficinas e cursos. As técnicas utilizadas foram principalmente observação participante e análise documental das duas peças.

Palavras-chave: Movimento de Mulheres Camponesas. Teatro. Formação Política.

\footnotetext{
* Licenciada em Educação do Campo, pela Universidade de Brasília-UnB, em parceria com Instituto Técnico de Capacitação e Pesquisa da Reforma Agrária- ITERRA. Especialista em Educação em Linguagens nas escolas do campo, pela Universidade de Brasília. Atua no Movimento de Mulheres Camponesas em Santa Catarina no Coletivo de Comunicação. Email: leti.mmc@hotmail.com
} 


\section{Introdução}

O objeto principal deste relato visa à descrição e análise de duas peças construídas coletivamente pelo grupo de teatro do Movimento de Mulheres Camponesas de Santa Catarina (MMC/ SC), em oficinas realizadas em 2008 e 2009. A primeira peça, intitulada Da luta se faz história, conta a história dos 25 anos de organização do MMC. A segunda, Histórias agroecológicas história de mulheres camponesas, aborda a importância da agroecologia como uma forma de produzir alimentos saudáveis e também como um meio de geração de renda para as camponesas.

A metodologia utilizada para analisar as peças relaciona o conteúdo destas com a forma como elas foram montadas, com o objetivo de perceber, neste processo, as influências que o conteúdo pode sofrer quando determinada forma é utilizada em sua montagem.

\section{O Grupo Teatral MMC: Resistência e Arte e a percepção das participantes}

O grupo teatral $M M C$ : Resistência e Arte foi criado no ano de 2008, com o objetivo de elaborar coletivamente uma peça para contar a história dos 25 anos do MMC/SC. As aulas de teatro, ou o curso, como foi chamado, aconteceram em quatro etapas. A primeira constituiu a composição do grupo e contou com a participação de 21 mulheres, de idades distintas entre 12 e mais de 60 anos. Essa diversidade caracteriza o perfil das militantes do movimento em Santa Catarina, constituído por mulheres de diferentes gerações, regiões e culturas.

Para a maioria do grupo, o MMC proporcionou o primeiro contato com o teatro e com isso, muitos os desafios foram colocados para todas. O principal limite que se colocou foi o de superar o medo de falar em público. Para contribuir nessa questão, o professor que orientou o grupo utilizou vários jogos teatrais. Os jogos tiveram papel fundamental na construção das peças, pois foi através destes que as mulheres, aos poucos, conseguiram se encontrar e se sentir parte do teatro do movimento.

Algumas das integrantes mais idosas do grupo tinham bastante domínio sobre a história do movimento, contribuindo significativamente para a definição do conteúdo da peça. Através de suas lembranças, foram construídas muitas cenas que 
constituíram a peça Da luta se faz história, como é o exemplo que se pode observar no trecho da cena 20.

Deputada 1: Não vais receber as lideranças das mulheres agricultoras?

Deputada 2: Não tenho nada com essa gentinha, nem sabia que elas existiam.

Deputada 1: Pois é deputada, mas tem muita gente do nosso estado.

Deputada 2: Mas com certeza nenhuma é eleitora minha, você que sempre ajudou a fazer essa bagunça, agora vire-se, afinal elas ainda fedem a vaca, eu não estou acostumada com este cheiro.

Fatos como este só foram possíveis de serem recuperados e incorporados no texto da peça porque no grupo havia conhecedoras da história do movimento. A cena anterior revela que a luta das mulheres camponesas busca conquistar espaços e reconhecimento na esfera política, esta que nem sempre se coloca como sensível e comprometida com suas causas.

No ano seguinte, em 2009, o grupo reuniu-se novamente para a realização da segunda peça Histórias agroecológicas, histórias de mulheres camponesas. Para esta peça, o grupo contou com novas integrantes, nova professora e também um novo conteúdo para ser estudado e adaptado à peça, colocando em destaque a agroecologia como uma das principais bandeiras de luta e prática feminista do MMC.

A luta central do MMC é contra o modelo capitalista e patriarcal e pela construção de uma nova sociedade com igualdade de direitos. Nesse sentido, assumimos como principal bandeira de luta o Projeto de Agricultura Camponesa Ecológico, com uma prática feminista, fundamentado na defesa da vida, na mudança das relações humanas e sociais e na conquista de direitos. (Bandeiras de luta do $\mathrm{MMC}$, material encontrado no site do MMC Brasil)

Com o objetivo de levar este debate também para fora do movimento, a segunda peça do grupo teve o importante papel de, através do teatro, mostrar para um público diversificado que as questões da agroecologia e alimentação saudável vão além das pessoas que moram no campo ou lidam com a terra.

Durante o processo de construção das peças, foi realizada a observação do grupo nos momentos de suas construções, preparação e ensaios para as apresentações do grupo. 
Quatro participantes do grupo responderam a um questionário elaborado para uma pesquisa, sendo duas jovens, uma dirigente do movimento e uma integrante que está no movimento a mais de quinze anos.

O objetivo das questões era perceber se o teatro trouxe algum tipo de benefício para o MMC e também para a vida particular das atrizes, assim como uma das entrevistadas descreve.

O teatro contribuiu muito comigo. No aspecto de sentir-me realizada, valorizada. Melhorando a maneira de me comunicar e enfrentar com coragem as lutas do dia-a-dia. Pela arte consigo expressar meus sentimentos. Para o MMC o teatro conseguiu atingir grande público no campo e na cidade, divulgando com arte as ações, conquistas e lutas das mulheres camponesas. $\mathrm{O}$ teatro ajudou a fortalecer a ideia sobre a importância da missão do MMC, de continuar a luta pela libertação da mulher, pela construção de uma agricultura camponesa agroecológica pela transformação da sociedade. (Maria Helena Kischner, 64 anos, Tunápolis/SC)

Para a militante mais jovem do movimento o teatro também contribuiu para melhorar e aumentar a bagagem das mesmas sobre os elementos da história, lutas e campanhas do movimento.

Pude conhecer mais o movimento, a história das mulheres, também mostrou a nossa luta pela nova sociedade (Fernanda Sebben, 19 anos, São Miguel do Oeste/SC).

Em relação aos benefícios que o teatro trouxe para o $\mathrm{MMC} /$ $\mathrm{SC}$, de uma forma geral, as atrizes entrevistadas também trazem questões importantes a serem levados em conta neste trabalho.

Conseguimos avançar nas formas de comunicação. Atingimos outros espaços como universidades, escolas, comunidades fazendo o debate sobre o MMC e sua missão, suas lutas, objetivos. Avançamos ainda no sentido de conseguir mais contatos para articular o movimento, mostrar que é possível fazer lutas, mobilizações e também cultura (Rozani Aparecida Schiavini, 43 anos, Itá/SC).

A forma como o público reagiu e recebeu as apresentações também é um elemento de análise, pois as peças são construídas não só para a militância do movimento, mas também para tornálo visível e reconhecido pela sociedade.

A reação geralmente já era percebida em cena. Muitas pessoas em suas falas no debate diziam ter sido tocadas profundamente, 
pois na família tinha algum tipo de ligação. Ou era da roça ou a mãe participava a tia ou alguém de sua relação, e ver as cenas lembrando muitos momentos de enfrentamento as questões de violência, direitos, política agrícola e outros os fazia sentir-se mais próximos a esta história. Muitas colocações vinham no sentido de parabenizar a nossa coragem de enfrentar o palco, de ser artista e camponesa ao mesmo tempo. Muita curiosidade também de como se dá isso na família. Mas tinha também os questionamentos de nossas lutas centrais, nossos desafios e para isso cada integrante da peça sentia se podia responder ou não. Daí todos participavam do debate. Não percebi nenhuma expressão negativa que desmotivasse o grupo a seguir em frente (Rozani Aparecida Schiavini, 43 anos, Itá/SC).

O público se demonstrava entusiasmado, surpreso, pois não esperavam que mulheres camponesas pudessem levar um debate tão importante como a agroecologia em forma de teatro. Perguntavam pra nós sobre a organização do grupo (Suzamara de Arruda, 32 anos, Chapecó/SC).

Pode-se perceber que o teatro, tanto na vida do MMC de Santa Catarina, quanto na vida particular das atrizes e militantes, foi visto de forma benéfica, pois cumpriu com seus objetivos principais, ou seja, trabalhar com teatro, mostrar que as mulheres do campo são capazes de fazê-lo e levar até a sociedade temas importantes como a agroecologia, além de fortalecer, dentro da organização, o papel da arte para o movimento.

\section{As peças}

\section{Da luta se faz história}

A peça, Da luta se faz história, foi a primeira peça elaborada e apresentada pelo grupo teatral do MMC: Resistência e Arte. Em 2008, o MMC-SC completou 25 anos de história e lutas e a elaboração desta peça foi uma das formas que o movimento encontrou para reconstruir a história e levá-la em forma de arte a várias regiões do estado. A peça foi apresentada nos municípios de Chapecó, São Miguel do Oeste, Tunápolis, Lages, Frei Rogério, Itapiranga, Xaxim, Nova Itaberaba e Descanso.

Esta peça conta a história dos 25 anos do movimento no estado, partindo de narrativas e experiências reais. Dessa forma, muitas das cenas da peça foram escritas a partir de depoimentos, 
lembranças das militantes e de fatos que marcaram a história de muitas lutas e conquistas de direitos para as mulheres camponesas. O conteúdo da peça se refere à esfera pública e à dimensão coletiva da luta das mulheres organizadas do MMC.

Da luta se faz história, é dividida em 25 cenas, o que é uma coincidência em relação aos 25 anos do movimento, pois não significa que cada cena equivale a um ano. As cenas alternamse em diálogos familiares, encontro de mulheres, reuniões, enfrentamento na rua, marchas, trazendo as músicas, os gritos de ordem e as poesias que fizeram parte dos 25 anos de história do MMC-SC. São, portanto, fragmentos que compõem uma unidade narrativa, uma totalidade, que é a história de luta do MMC.

Por ser uma peça que conta uma história que começou há 25 anos, inicia com uma avó relembrando este passado e contando aos seus netos. Estabelecendo uma comparação entre o presente e o passado, a avó caracteriza o passado como um momento bom de sua vida, principalmente em relação a qualidade dos alimentos, que eram produzidos sem o uso de veneno nas lavouras.

A avó relata na história a Guerra do Contestado, que representa o marco da situação de repressão e exploração de camponeses do estado, no início do século XX, onde muitos foram expulsos de suas terras em nome do "progresso" e do interesse de grandes empresas Norte Americanas, que se instalaram na região para a construção de ferrovias. A peça estabelece também uma relação com a história de outras mulheres camponesas, que não fizeram parte do movimento, mas que também lutaram por seus direitos, por suas terras, pelas suas vidas. É uma relação política com a situação em que os camponeses e camponesas da época se encontravam, sendo obrigados, em conflito armado, a deixar suas casas, suas comunidades. Essa articulação entre tempos históricos distintos é uma das características do teatro épico, ou seja, permite à crítica a dinâmica destrutiva da lógica de progresso da classe dominante.

A cena de número seis mostra um sistema de submissão, que tem a mulher como propriedade do homem. Pelo fato de ser casada, a mulher é vista como simplesmente a "mulher do seu Severino" e por isso não tem nem seus próprios documentos. Tais características reforçam o sistema patriarcal, em que o homem está acima de tudo, como uma espécie de "cabeça” ou alicerce da família.

Nesta cena, há destaque também para o reconhecimento da profissão de agricultora, assim como a personagem desta cena, 
há muitas camponesas que não se identificam como agricultoras, enquanto profissão reconhecida, na medida em que há uma imposição da ideologia do mercado capitalista que faz com que as mulheres que sobrevivem da terra pensem que profissão é somente aquela que gera renda direta e um salário no final de cada mês.

A ideologia patriarcal imposta pela sociedade reforça a ideia de que o que a mulher desenvolve em casa ou na horta são suas obrigações, o que não permite o reconhecimento destas atividades como um trabalho, mas apenas como tarefas rotineiras, sendo que a atividade desenvolvida pelo homem da casa, esta sim, seja um trabalho que merece ser melhor reconhecido, pois é rentável financeiramente.

Este vai e vem no tempo revela como a peça é estruturada: a avó, ao contar a história para os netos, deixa claro que se trata de uma narrativa que é lembrada por uma pessoa que realmente viveu aquela época e que recorda com tristezas e alegrias um cenário político de 25 anos do Movimento de Mulheres Camponesas de Santa Catarina.

A partir da cena oito, a história de organização das mulheres agricultoras ${ }^{1}$ se inicia, enquanto movimento, retratando as necessidades, dificuldades, demandas, limites que as mulheres do campo enfrentavam e ainda enfrentam, ou seja, há preocupação com o processo da causalidade histórica. $\mathrm{Na}$ peça os problemas que as mulheres enfrentam aparentemente são individuais, mas as questões individuais se transformam em uma necessidade de organização coletiva. $\mathrm{Na}$ estrutura da peça, sobre essa questão, pode-se identificar um problema, a necessidade de organização coletiva surge a partir dos entraves que as mulheres enfrentam geralmente no âmbito familiar. $O$ que não está explícito na forma e nem no conteúdo, é a maneira como se dá esse processo de reconhecimento de que há uma situação de submissão, por exemplo. Um exemplo é a cena seis, em que a personagem Joana, sozinha, não percebe a situação em que vive, sendo possível afirmar que a cena naturaliza a condição da personagem.

O processo de início da organização das agricultoras e do movimento, é contado na peça tal como aconteceu, com poucas mulheres, em um município pequeno, onde reuniões foram realizadas partindo dos problemas concretos vividos pelas mulheres. O momento de elaboração desta peça em grupo possibilitou que as atrizes trouxessem para o grupo, suas experiências no movimento ou experiências de outras companheiras. E o fato de a história ser
1 Período em que o movimento intitulava-se MMA, e ainda não se usava a expressão camponesa e sim agricultora para se referir às mulheres que vivem da terra. 
real, fazia com que em muitos momentos durante as apresentações, quem estava assistindo a peça se emocionasse, se divertisse ou se indignasse com determinada situação representada, principalmente, se se reconhecessem enquanto parte da história e da luta.

Aqui vale destacar o efeito que a peça pode causar no público, ou seja, assim como as cenas da peça podem causar o efeito de reconhecimento ou empatia, as espectadoras podem se reconhecer no curso histórico da luta coletiva. Porém, o processo de reconhecimento também pode ter efeito alienador, a partir do momento em que a identificação se torna individual e suprime o reconhecimento coletivo. Um exemplo de identificação individual é o que acontece nas telenovelas, em que a forma dramática traz situações que são facilmente possíveis de serem comparadas com a realidade, logo, induz quem assiste a pensar que a arte, no caso da telenovela, realmente imita a vida.

A peça deixa claro que no processo de inicio da organização, as mulheres sofreram opressão dentro e fora de casa, dos maridos e da sociedade patriarcal, que afirma que o espaço público não é um espaço para mulheres.

No campo, a violência contra as mulheres também acontece, talvez de forma mais silenciada do que no espaço urbano, pois no campo muitas mulheres quando são violentadas tendem a permanecer invisibilizadas, pelo fato de estarem mais restritas ao espaço doméstico, onde as situações de violência acabam sendo camufladas. Esta situação também é representada na peça através de uma conversa entre as próprias mulheres, sendo que uma conta para a outra que sofre agressão do marido por tentar contrariálo, ou seja, esta cena, que poderia ser uma cena forte para ser representada, não aparece de forma explícita na peça. Ou seja, esteticamente a forma não potencializa a força que a cena poderia ter na estrutura da peça. Ela poderia ser abordada de maneira diferente, como, por exemplo, trazendo dados reais da violência cometida contra a mulher do campo.

A frase "Que nada nos limite, que nada nos defina, que nada nos sujeite! Que a liberdade seja nossa própria substancia!", expressada por uma das atrizes em um momento de término da reunião das mulheres, mostra a indignação diante da situação representada na cena anterior. Dessa forma, há a diminuição da passividade com que a cena trata o tema, mas ainda não soluciona o problema estético ali contido, pois a atriz fala de forma distanciada, de fora de sua personagem.

REVISTA GRIFOS - N. 34/34 - 2013 
Já nos primeiros encontros em que as mulheres se reuniam

para conversar e debater, aparecem as contradições internas do grupo, mas que na realidade são contradições que são fortemente identificadas na sociedade, principalmente em relação à educação que as mulheres do campo receberam. Muitas delas foram, e ainda são, educadas para o casamento e crescem aprendendo a cuidar dos irmãos, da casa, da alimentação da família, como se essa fosse a principal formação necessária para as mulheres.

O que é muito interessante na peça é que fica claro que, mesmo depois de surgir a organização das mulheres, os problemas não são resolvidos, ou seja, os conflitos não desaparecem das cenas. Dessa forma, a peça não se transforma em uma peça idealista, como poderia ser, caso mostrasse que, depois da chegada do movimento em uma determinada comunidade, por exemplo, todas as famílias passassem a produzir somente produtos agroecológicos.

A questão do êxodo rural é uma consequência principalmente do endividamento das famílias em bancos. $\mathrm{O}$ êxodo chegou na agricultura junto com o pacote químico de produção, o uso de agrotóxicos nas lavouras com a promessa de melhorar a produção e acima de tudo ganhar mais dinheiro, a criação de suínos integrados com grandes empresas, fazendo com que os agricultores realizassem grandes empréstimos para pagar outras dívidas com as empresas. Aqueles que não conseguiram pagar essas dívidas tiveram que vender as terras e migrar para a cidade. Esta é uma situação vivida por muitas famílias camponesas, principalmente com a chegada do capital no campo, através da lógica da industrialização, que fez com que as famílias se endividassem de tal forma que não lhes restou outra alternativa a não ser vender as terras e migrar para a cidade a procura de emprego.

A cena que retrata esse contexto, se refere a uma história vivenciada na esfera familiar, mas nem por isso deixa de retratar uma questão política vivida por muitas famílias camponesas.

$\mathrm{Na}$ peça, a música "Pra mudar a sociedade" entra em cena junto as bandeiras, representando o momento em que a luta, a organização coletiva, é retratada na peça. Esta música também faz parte dos 25 anos de história do movimento.

A luta pela documentação das mulheres do campo também faz parte das muitas lutas do MMC de Santa Catarina, pois muitas não tinham documento próprio e dependiam dos pais ou do marido para comprar até suas roupas. Junto à luta pela documentação, também ocorreu a luta pelo reconhecimento 
de agricultora como profissão, e consequentemente o direito à aposentadoria da mulher agricultora com cinquenta e cinco anos de idade.

As cenas que seguem mostram que muitos direitos foram conquistados, e que tais direitos foram garantidos através de muita luta e confrontos, inclusive com a polícia. Os confrontos também aconteceram devido ao descaso do poder público. Estas cenas significam uma forma de equilibrar, na peça, a relação entre épico e dramático, ou seja, após cenas dramáticas, aparecem cenas de conflito na esfera pública, caracterizando as lutas do movimento. Vale salientar, que essa peça tinha como objetivo de contar a história dos 25 anos do MMC de Santa Catarina, por isso as cenas perpassam o épico e o dramático, o privado e o público, pois muitas lutas das mulheres aconteceram inicialmente dentro de suas próprias casas. Isso demonstra a forma de oposição ao sistema patriarcal e machista reproduzidos por muitos maridos, mesmo que, neste primeiro momento, questões como o patriarcado e o capitalismo não estivessem na pauta de luta e nas discussões do movimento.

A peça termina com todas as mulheres no palco, intercalando cenas diversas de trabalho e de luta, tendo como trilha sonora a música "Mulher da Roça", que mostra a importância da mulher camponesa organizada em movimento lutando e trabalhando.

Da luta se faz bistória tem um tempo de duração de aproximadamente 60 minutos, sendo que a estrutura da peça faz com que a mesma não se torne cansativa para quem está assistindo, pois possibilita durante este tempo várias "surpresas" para a platéia, na medida em que o público não sabe o que virá depois de cada cena, causando uma expectativa para o público constituído por militantes e seus familiares.

\section{Histórias Agroecológicas, Histórias de Mulberes Camponesas}

No ano de 2009, o grupo de teatro do MMC sofreu alterações na composição do coletivo, pois algumas companheiras saíram e outras ingressaram para compor este. Isso se deu pelo fato de que o movimento optou por convidar novas integrantes para compor o grupo, já que o grupo de teatro também é considerado uma forma de entrada na militância do movimento. Muitas mulheres que saíram do grupo assumiram outras atividades ou deram continuidade em suas tarefas no movimento. Nesta nova etapa, o 
objetivo do grupo e do MMC continua sendo o de levar o debate do movimento para a sociedade. Desta vez, as apresentações do grupo atingiram outros públicos em espaços como universidades e escolas, não se restringindo ao público militante e seus familiares.

O tema abordado proporcionou ao público conhecer uma das bandeiras de luta do MMC no estado, a agroecologia e a importância da produção de alimentos saudáveis, que é também uma das principais discussões que o movimento faz com suas militantes. $\mathrm{O}$ movimento acredita que o tema também deva ser discutido com a sociedade em geral, já que a alimentação saudável não vem sendo a principal preocupação da população nos últimos tempos.

Da primeira peça para a segunda, se observarmos a escolha dos temas, há um processo de amadurecimento do uso do teatro como propaganda do MMC, pois, ao focar na questão da alimentação saudável, ele dialoga diretamente com o interesse dos consumidores de alimentos, sejam eles do campo ou da cidade. $\mathrm{Na}$ peça Luta se faz História, o objetivo era o de retomar a história do MMC, com a intenção de tornar pública e conhecida através do teatro uma história para aqueles que não a conheciam.

A correria das cidades e consequentemente dos trabalhadores (as), faz com que a alimentação saudável não seja uma prioridade, na medida em que, por causa da falta de tempo, as pessoas optam pelas "facilidades", ou seja, pelos produtos que levam menos tempo para ficar prontos para o consumo, os quais possuem uma maior quantidade de produtos químicos em sua composição. Por estas e outras razões, a escolha do movimento foi de realizar uma peça que abordasse a agroecologia e a importância da alimentação saudável.

Assim como a primeira, esta peça também foi apresentada em vários municípios do estado, entre os quais se destacam Chapecó, Itá, São Joaquim, Florianópolis, Palmeira e Urussanga. Neste segundo momento, o público das cidades foi o maior alvo das apresentações, isso devido a abrangência do tema. O movimento acredita que a população urbana deve tomar conhecimento da importância de uma alimentação de qualidade, pois o uso de veneno nos alimentos não coloca em risco somente a saúde do agricultor, mas também de quem consome o alimento envenenado.

A peça inicia com uma atmosfera mística, relembrando as bruxas, ervas, aromas e música. Tanto a cena de início, quanto a que a segue, causa a impressão de continuidade da primeira 
peça produzida pelo grupo, pois já na primeira fala de uma mulher camponesa transparece a acumulação do conhecimento em relação aos venenos, insumos químicos, por exemplo. Situação essa que é possível perceber no trecho a seguir, em que uma mulher camponesa ouve no rádio propagandas de lojas de roupas veiculadas no programa do movimento no rádio e fica indignada.

"Radialista 1 (animada) - Boa tarde! Iniciamos mais um programa da mulher camponesa. Para elas e para eles, mas feito inteiramente por elas.

Interferência- (interrompendo fazendo propaganda) De mulher pra mulher Patriciaaa!

Radialista 1- Opa, tá havendo uma interferência... Interferência perniciosa é propaganda enganosa! (apaga a luz)

$\mathrm{Na}$ casa mãe filha estão juntas, mais a direita do palco (cortina). Uma escolhe sementes enquanto a outra lê algo. Uma mesa e duas cadeiras e uma peneira com sementes, canecas, um bule e materiais escolares para a filha.

Mãe Camponesa - Propaganda enganosa, conheço bem! (de forma pausada) Quando não é de roupas, maquiagem, sapatos em promoção, são as de veneno, insumos, sementes transgênicas...Por isso oh!(mostra as sementes para a filha), eu tenho as minhas crioulas!!

Radialista 2 - PSIUUU... fala baixo o programa tá no ar menina! (apaga a luz)

Mãe Camponesa - É mesmo, depois da revolução verde nós não sossegamos mais minha filha. Nossa família e assim como a terra, padeceu muito! Mas você não pegou essa época, não é minha filha!? Com informação e persistência nos já demos à volta. Filha, a mãe tá falando contigo, você anda muito distraída..., aos poucos você vai entendendo!(Apaga luz)"

O tema escolhido para esta peça vem do acúmulo de muitos anos de debate enquanto movimento social feminista e camponês. $\mathrm{O}$ movimento tem a agroecologia como uma questão que deve ser debatida permanentemente, conforme pode ser identificado neste trecho de um texto produzido coletivamente pelo movimento e publicado pela Revista Camponesa. 
A agroecologia precisa proporcionar a autonomia das famílias no auto-sustento e renda, integrando campo e cidade. Para isso, é preciso buscar formas alternativas de energia, de acesso e controle dos meios de produção, distribuir renda inclusive para as mulheres camponesas, valorizando e reconhecendo o trabalho da mulher na produção de alimentos diversificados e saudáveis. (Revista CAMPONESA/MMC-SC, Dezembro 2007, ano II, revista II)

A agroecologia não está ligada apenas à produção, mas também possui uma grande relação com a saúde e a geração de renda para as famílias camponesas, principalmente para as mulheres, na medida em que muitas conseguem sua autonomia financeira através da produção agroecológica em suas unidades de produção. A agroecologia está ligada também ao Projeto de Agricultura Camponesa, que é a principal questão defendida pelo MMC. Segundo o material produzido pelo MMC nacional sobre saúde, nos últimos 20 anos aconteceram mudanças no modo de vida alimentar, ocorridas a partir da imposição do modelo químico agrícola. Hoje, é comum encontrarmos também na casa de agricultores, refrigerantes, margarina, alimentos com alto índice de conservantes, corantes, aditivos químicos, produtos estes que foram sendo adicionados à mesa dos agricultores.

O tema, portanto, tem sua eficácia política, não só caracterizada pela agroecologia, mas também por uma das características formais da peça, as cenas breves. Estas cenas são, momentos em que se renovam os conflitos da história, chamando a atenção do espectador.

A peça inicia indo direto ao ponto que será abordado. $\mathrm{O}$ que de certa maneira é inesperado na estrutura da peça, na medida em que apresenta as mulheres com um grande conhecimento e reconhecimento sobre a importância do movimento e a agroecologia. Neste sentido, à primeira vista a peça não segue um padrão sistemático, em que as camponesas precisam da chegada do movimento para tomar consciência dos problemas. Há entre as mulheres um processo de consciência avançado em relação à importância do MMC.

Algumas contradições são colocadas no programa de rádio, que segue na peça realizado pelas mulheres camponesas do $\mathrm{MMC}$, retratando a realidade de alguns municípios onde o MMC está organizado, em que as rádios sedem um espaço para o movimento. 
A cena nove apresenta um programa de rádio do movimento, no qual ocorre um debate sobre o tema da agroecologia entre um agrônomo, um secretário de agricultura e uma liderança do MMC:

Catiane (Radialista 1) - Bom dia ouvintes da rádio camponesa. Estamos aqui para mais um programa de debate sobre agroecologia. Hoje contamos com a presença do Secretário da Agricultura, uma agrônoma e uma liderança do Movimento de Mulheres Camponesas.

Primeiramente conversamos com a representante do Movimento de Mulheres, Beatriz que vai falar aos nossos ouvintes um pouco do trabalho desenvolvido no campo? Porque você se identifica como camponesa? Bom dia!

Beatriz (Liderança do Movimento) - Bom dia, Catiane, e bom dia a todos os ouvintes. Somos camponesas porque temos uma relação de cuidado e respeito com o solo, terra, com a natureza e somos parte dela. Nossa missão é a libertação da mulher, a construção do projeto de agricultura camponesa agroecológico através das ações de recuperação, preservação e conservação do saber popular em plantas medicinais, sementes crioulas de hortaliças, produção de alimentos saudáveis, proteção das nascentes e fontes de água. Por isso lutamos contra os transgênicos, agrotóxicos, monocultivos e todas as políticas do agronegócio.

Catiane (radialista 1) - Obrigada Beatriz pela sua contribuição. Agora ouviremos a opinião da senhora Maria Helena, agrônoma... que irá falar sobre a produção agroecológica. Bom dia.

Maria Helena (agrônoma) - Bom dia ouvintes. Penso que a agroecologia é muito interessante. Mas hoje temos muita pesquisa para o melhoramento da produção com novas tecnologias que nos permitem produzir muito mais com mais lucro.

Beatriz (Liderança do Movimento) - Com licença. Mas, lucro pra quem? E como? Os investimentos em melhoramento normalmente tem servido os interesses das empresas transnacionais. Já para a produção agroecológica os investimentos são menores.

Catiane (radialista 1) - Muito bem, mas vamos ouvir a opinião do Secretário da Agricultura do município senhor Gilberto. Qual a sua posição sobre este assunto? Bom dia.

Aglaé (Secretario da Agricultura): Bom dia a todos os ouvintes, especialmente aos munícipes. Como representante do poder pú-

REVISTA GRIFOS - N. 34/34 - 2013 
blico, gostaria de agradecer a rádio por mais essa oportunidade de estar dialogando com o nosso povo. Aproveito para divulgar os nossos programas de apoio à Agricultura Familiar. Eu, juntamente com o senhor prefeito estamos desenvolvendo o programa de calcário e incentivando o reflorestamento, distribuindo mudas de eucalipto e pinus.

Beatriz (Liderança do Movimento) - Mais uma vez tenho que me posicionar. Porque eucalipto e pinus para nós não é reflorestamento, pois acaba com a biodiversidade e a vida do nosso solo.

Catiane (radialista 1) - E a senhora agrônoma, o que tem a dizer sobre isso?

Maria Helena (Agrônoma) - Ela tem razão. Porém temos que ver que a biodiversidade e essa forma de produção é muito lenta e não dá lucro a curto prazo. Ocupa muito espaço, tirando o lugar de produção de grãos e criação de animais em grande escala.

Aglaê (Secretario da Agricultura) - Mas também temos que pensar também na arrecadação para o município e se só cuidar do meio ambiente não vamos sobreviver na agricultura e os municípios vão ter dificuldade em ter recursos.

Catiane (radialista 1) - Para encerrar o nosso programa queria chamar atenção de todos ouvintes em especial a todos os consumidores que precisamos nos unir campo e cidade para termos uma alimentação saudável e mais diversificada. E essa mudança somente irá acontecer a partir da nossa organização e conscientização.

Muito obrigado pela presença e participação neste debate. Bom dia a todos e a todas ouvintes, voltamos amanhã neste mesmo horário.

Avaliamos que, pelo fato desta cena apenas reproduzir as vozes dos participantes do debate, talvez não tenha sido a melhor forma de o grupo discutir esta temática, na medida em que há um interrupção na dinâmica da peça em relação à cena anterior, o que compromete a atenção do público e do grupo quanto à importância do assunto. Entretanto, a riqueza do debate reside no confronto de ideias e no posicionamento explícito da liderança do movimento em relação à questão debatida.

Neste sentido, se observa uma limitação em relação à ausência de uma mediação que explorasse mais as contradições existentes nas posições das partes que compunham o debate, sendo que a radialista se limitou apenas a ouvir os argumentos. 
A cena dez traz presente o coro, deixando cada vez mais claro qual é a proposta do movimento no que se refere à questão da terra.

Se a terra for cuidada, Preservada, Se houver investimento e políticas públicas, Se houver reforma agrária, Se a cultura camponesa for respeitada e valorizada, Se a biodiversidade for conservada, É possível produzir alimentos saudáveis para o auto sustento e renda.

A participação do coro e a entrada da música Terra, do cantor Pedro Munhoz, escolhida para representar a cena, são fundamentais para estabelecer uma relação empática com o público, tornando a cena muito bonita esteticamente.

A cena seguinte apresenta acima de tudo um caráter de denúncia ao descaso do governo do Estado, o que evidencia a importância da mobilização e da ação nas ruas, o que caracteriza as mulheres camponesas organizadas em movimento, que acreditam na transformação da sociedade através da luta.

As técnicas utilizadas pelo grupo nesta peça, sombras e rádio, mostram que mulheres camponesas de diferentes faixas etárias têm condições de se aperfeiçoarem tecnicamente na linguagem teatral. Essa é uma característica importante a ser destacada, pois o grupo é bastante heterogêneo em relação à idade das militantes, experienciando diferentes níveis de aprendizado e de conhecimento sobre os temas retratados nas peças, caracterizando o trabalho coletivo de uma forma na qual todas pudessem contribuir e participar na construção.

A cena quinze representa o que já foi ressaltado anteriormente. A falta de tempo dos trabalhadores (as) faz com que optem pelo que é mais fácil, e nem sempre o que é mais fácil é melhor e mais saudável. Na estrutura das cenas, o contraponto a essas questões junta-se à ideia de evidenciar as questões que o movimento vem discutindo com suas militantes e também com a sociedade em geral, as quais precisam ser debatidas, principalmente por se tratar de saúde e preservação do meio ambiente. A peça revela também uma forma de "mexer" com a ordem, pois são mulheres camponesas fazendo teatro e denunciando ao mesmo tempo. $\mathrm{O}$ nascimento de uma criança no final da peça representa simbolicamente a necessidade de continuidade desta luta. 


\section{Considerações finais}

Ao analisar as duas peças elaboradas e interpretadas pelo grupo, e de também participar dos momentos de ensaio e apresentações, é possível afirmar que a arte através do teatro cumpre o seu principal papel, que é o de desvelar as contradições existentes na sociedade e, dessa forma, provocar no público a reflexão, tornando-o ativo diante da peça.

Constatou-se também que com o teatro foi possível a entrada de novas militantes no MMC, as quais tiveram seu primeiro contato com o movimento através do grupo de teatro, possibilitando o conhecimento melhor a luta do movimento.

A análise das técnicas utilizadas pelo grupo foi importante para a percepção da eficácia que elas podem ter ou não no sentido de aprofundar as temáticas propostas. Finalmente, é importante ressaltar o esforço e o avanço que esta atividade representa para movimento, pois além de permitir que as mulheres camponesas se empoderem fazendo arte, as mesmas levam a mensagem do MMC para a sociedade através do teatro.

\section{Referências}

MMC. Bandeiras de Luta do Movimento de Mulheres Camponesas. Disponível em <http://www.mmcbrasil.com.br> . Acesso em: 10 fev. 2011.

MOVIMENTO DE MULHERES CAMPONESAS EM SANTA CATARINA. MMC/SC Uma história de organização, lutas e conquistas. Chapecó: Gráfica Rota, 2008.

MOVIMENTO DE MULHERES CAMPONESAS EM SANTA CATARINA. MMC/SC. Mulheres Camponesas em defesa da saúde e da vida. Chapecó: Gráfica Rota, 2007.

MOVIMENTO DE MULHERES CAMPONESAS EM SANTA CATARINA. Revista Camponesa II Chapecó: Gráfica Rota, 2008.

PALUDO. Conceição (Org.). Mulheres, resistência e luta em defesa da vida. São Leopoldo: CEBI, 2009.

VINCENZO, Elza Cunha de. Um teatro da mulher: dramaturgia feminina no palco brasileiro contemporâneo. São Paulo: Perspectiva: EDUSP, 1992. 